\title{
Will Health Canada follow US move to eliminate trans fats?
}

$\mathrm{T}$ hey might not even notice, but Americans may soon be eating healthier microwave popcorn, frozen pizza, frosting and more as the US Food and Drug Administration (FDA) moves to turn foods containing unhealthy trans fats into a thing of the past.

The amount of trans fat in the US food supply has been declining for two decades, partly due to pressure on the food industry, better food labelling and growing public understanding about the health risks. Now the FDA wants to banish trans fats altogether, a step the agency estimates could save 7000 lives and prevent 20000 heart attacks each year in the United States.

The move is long overdue, according to David Levitsky, a professor of nutritional sciences at Cornell University in Ithaca, New York. The evidence has been clear for at least 20 years on the dangers of trans fats, says Levitsky, who predicts that many nations will eventually act to eliminate them from their foods.

"It's not going to immediately cause a drop in heart disease," he says of the FDA action. "But it's one small step, and that's all we can do is take a series of small steps toward improving the health of the nation."

Though consumption of trans fats is also declining in Canada, Canadian health advocates are seeking stronger action to eliminate them outright, and are hoping action taken by the FDA will have a spillover effect to the north.

"You have to take them out of the food supply," says Bill Jeffrey, Canadian national coordinator of the Centre for Science in the Public Interest. "Even if one company is selling food with 1 gram, that's creating an unacceptable health risk."

Jeffrey says the FDA action could result in healthier products being shipped from the US to Canada - or it could turn Canada into a dumping ground for cheaper and more dangerous foods.

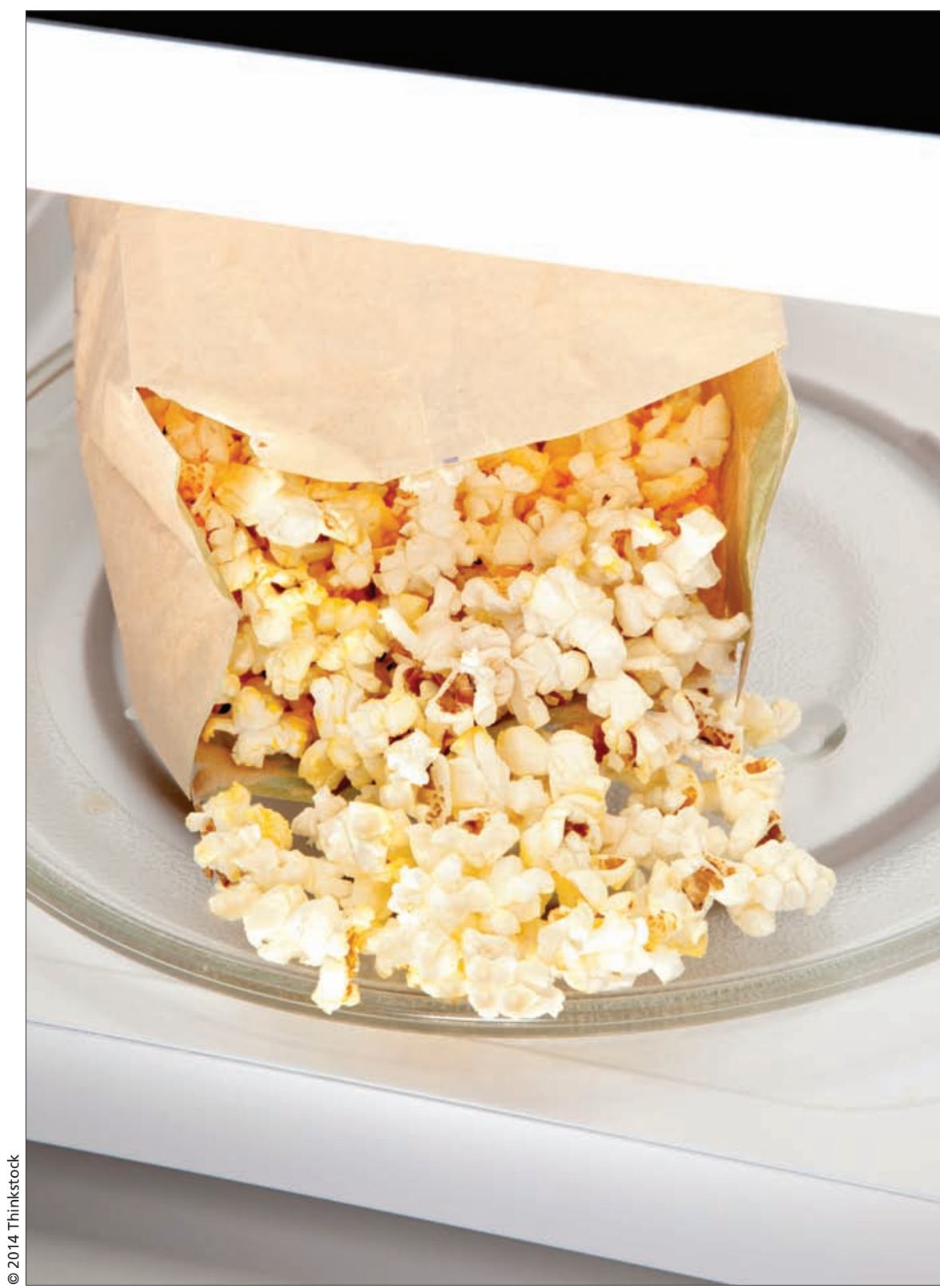

Foods most likely to contain trans fats include microwave popcorn, frozen pizza, readymade frosting, stick margarines and coffee creamer.

After the FDA announcement, Jeffrey sent a letter to federal Health Minister Rona Ambrose urging her to follow the US lead "by finally issuing Canadian regulations to restrict the manufacture, sale and use in manufacturing of partially hydrogenated oils."

In 2007, Canada set voluntary trans fat reduction targets and established monitoring and labelling rules that led to significant reductions. Though the government stopped its monitoring program in 2009 , research indicates that consumption of trans fats in Canada has continued to decline, says Mary L'Abbé, nutritional sciences chair at the University of Toronto in Ontario and a former Health Canada 
official who worked on investigations into trans fats.

But there are still a few food categories, such as frostings and stick margarine, with fairly high amounts of trans fats, she says, also noting that although many Canadian manufacturers have eliminated trans fats from their formulations, there are still some problematic holdouts.

Before settling on a new approach to get the remaining trans fats out of Canadian foods, however, it makes sense to first watch how things unfold in the US, says L'Abbé.

The US began its process by issuing a preliminary determination in early November stating that partially hydrogenated oils - the source of trans fats — should no longer be included on the list of food additives that are "generally recognized as safe."

With that, the agency opened a 60day comment period to collect more information and get input from the food industry about how much time manufacturers and restaurants would need to phase out trans fats.

If a final determination is approved once the comment period ends, food makers would have to petition the federal government after the phase-in period for permission to use partially hydrogenated oils, and they would be unlikely to win approval. The FDA action would not affect the small amount of trans fats naturally occurring in certain meat and dairy products.

Already, food makers have found ways to eliminate partially hydrogenated oils from a large number of products, and US consumption of trans fats has fallen from 4.6 grams per day in 2003 to about 1 gram in 2012, according to the FDA.

Though many large restaurant chains and food manufacturers found they were able to remove partially hydrogenated oils without harming taste or drawing complaints, they are still used in some processed foods to stabilize baking properties, increase shelf life and improve flavour. The products most likely to contain them include microwave popcorn, frozen pizza, ready-made frosting, stick margarines and coffee creamer. - Nancy Benac, Washington, DC

CMAJ 2014. DOI:10.1503/cmaj.109-4664 